\title{
PREVENÇÃO DO CARCINOMA HEPATOCELULAR
}

\section{Prevention of hepatocellular carcinoma}

\author{
Francine PAPAIORDANOU, Marcelo Augusto Fontenelle RIBEIRO-JUNIOR, William Abrão SAAD
}

\begin{abstract}
Papiordanou F, Ribeiro-Jr MAF, Saad WA. Prevenção do carcinoma hepatocelular. ABCD Arq Bras Cir Dig 2009;22(2):115-9
RESUMO - Introdução - O carcinoma hepatocelular $(\mathrm{CHC})$ é uma das principais doenças malignas da atualidade. Devido à alta incidência e prognóstico habitualmente sombrio torna-se relevante a necessidade de ações preventivas, levando em consideração a característica peculiar de sua etiologia: estrita relação de sua gênese a fatores ambientais. Os principais fatores de risco geograficamente melhor distribuídos são a associação de CHC com infecções por hepatite B crônica, hepatite C e cirrose hepática (associação em mais de $80 \%$ dos casos), independente de seu fator causal. Ele é o quinto tumor maligno mais frequente em todo o mundo ( $5^{\circ} \mathrm{em}$ homens e $8^{\circ} \mathrm{em}$ mulheres); representa $85 \%$ dos tumores hepáticos primários e é responsável por quase dois terços das mortes por câncer. Método - Revisão da literatura nacional e internacional dos últimos 12 anos (1997-2009), de 25 artigos pesquisados nas bases eletrônicas de dados MedLine, Scielo e LILACS. Conclusão - Apesar dos avanços científicos e da implementação de medidas para detecção precoce do $\mathrm{CHC}$ em pacientes pertencentes a grupos de risco, não houve melhora na taxa de sobrevida durante as três últimas décadas. O motivo que pode explicar esse fato é que a maioria dos pacientes começa a apresentar sintomas somente quando a doença já está em estágio avançado, e nesse caso as opções terapêuticas são limitadas.

DESCRITORES - Carcinoma hepatocelular. Neoplasia hepática. Prevenção. Fatores de risco
\end{abstract}

\section{INTRODUÇÃO}

O carcinoma hepatocelular $(\mathrm{CHC})$ é uma das principais doenças malignas da atualidade. Sua elevada incidência e seu prognóstico habitualmente sombrio indicam a relevante necessidade de ações preventivas, principalmente por característica peculiar de sua etiologia, e estrita relação de sua gênese a fatores ambientais. A grande maioria dos cânceres de fígado resulta de complicações de quadros de cirroses ativas ou inativas; no entanto, alguns se desenvolvem em órgãos praticamente sem alterações histológicas relativas, o que justifica a existência da influência desses fatores e enfatiza a necessidade e importância de profilaxia adequada ${ }^{13}$.

$\mathrm{O} \mathrm{CHC}$ é o quinto tumor maligno mais frequente em todo o mundo ( $5^{\circ} \mathrm{em}$ homens e $8^{\circ} \mathrm{em}$ mulheres); representa $85 \%$ dos tumores hepáticos primários e é responsável por quase dois terços das mortes por câncer ${ }^{13}$.

Devido ao rápido crescimento tumoral e à ausência de sintomas nos estágios precoces da doença, frequentemente quando o paciente procura ajuda médica o tumor já está em estágio avançado ${ }^{22}$.

O prognóstico é ruim na maioria dos casos e a taxa de sobrevida em cinco anos é em média 5\% em pacientes nos pacientes sintomáticos ${ }^{13}$.

A patogênese do CHC é muito complexa e envolve alte-

Trabalho realizado na Universidade Cidade de São Paulo UNICID, São Paulo, SP, Brasil.

Endereço para correspondência: Marcelo Augusto Fontenelle Ribeiro Junior, e-mail: mribeiro@cwaynet.com.br rações na estrutura ou expressão de genes supressores de tumor, oncogenes e possivelmente um acúmulo de alterações gênicas durante ciclos repetidos de divisão celular, como rearranjos cromossômicos e associação com mecanismos de reparo de erros de pareamento de DNA deficientes. Todos esses processos estão relacionados na maioria das vezes a uma doença hepática crônica subjacente, e podem resultar em transformação neoplásica dos hepatócitos ${ }^{3,12}$.

Os principais fatores de risco geograficamente melhor distribuídos são a associação de $\mathrm{CHC}$ com infecções por hepatite $\mathrm{B}$ crônica (HBV), hepatite C (HCV) e cirrose hepática (associação em mais de $80 \%$ dos casos), independente de seu fator causal, que podem ser inúmeros ${ }^{1,2,3,6}$.

Alguns fatores de risco para o $\mathrm{CHC}$ são especialmente importantes em determinadas regiões geográficas, como a exposição a aflatoxinas, esquistossomose, sobrecarga de ferro na dieta e exposição a água de lagos e rios contaminados por algas azuis que produzem microcistinas ${ }^{13}$.

Fatores de risco menores incluem contraceptivos orais, tabagismo, porfiria, resistência insulínica, uso de anabolizantes, exposição laboral a clorovinil, administração de metotrexato e dióxido de tório, contaminação da água por arsênico ${ }^{13}$.

\section{Estágios de prevenção}

A prevenção do carcinoma hepatocelular é dividida em três níveis

- Prevenção primária: consiste em evitar que um agente etiológico inicie o processo carcinogênico. Inclui evitar, eliminar ou neutralizar o carcinógeno. A prevenção primária 
depende do conhecimento dos fatores de risco passíveis de prevenção específicos para este tumor.

- Prevenção secundária: necessita que haja intervenção no metabolismo do carcinógeno, prevenindo que este atinja seu tecido alvo.

- Prevenção terciária: baseia-se em tentar evitar que uma lesão pré-maligna progrida para o câncer propriamente dito.

Dos fatores de risco listados, apenas alguns deles são passíveis de prevenção.

\section{Infeç̧ão pelo vírus da hepatite B (VHB)}

A infecção pelo VHB é em todo o mundo considerada a principal causa de $\mathrm{CHC}^{6,21}$ representando cerca de $80 \%$ em áreas de incidência elevada. Mais de um bilhão da população mundial apresenta evidência sorológica de infecção presente ou prévia pelo VHB (aproximadamente $6 \%$ da população mundial é portadora crônica da doença) $)^{9,13}$. O VHB é atualmente o fator carcinogênico ambiental mais importante (juntamente com o tabaco).

A infecção é predominantemente adquirida na infância ou no período perinatal, e quando adquirida nessas fases apresenta 80-90\% de chance de se tornar crônica. Os indivíduos infectados precocemente são os mais suscetíveis a desenvolver o $\mathrm{CHC}$, e com a presença de cirrose hepática, esse risco aumenta exponencialmente. $\mathrm{O}$ aparecimento do $\mathrm{CHC}$ é rara em indivíduos sem cirrose $^{12}$. Outras formas de contágio do vírus são pelo uso compartilhado de seringas e contato sexual desprotegido.

$\mathrm{O}$ vírus leva à inflamação do parênquima hepático, aumentando a proliferação dos hepatócitos; gera integração do DNA-VHB ao DNA das células do hospedeiro e ativa proteínas específicas do VHB interagindo com os genes presentes no fígado. $\mathrm{O}$ ciclo celular pode ser ativado por proliferação compensatória em resposta a necroinflamação local ou por superexpressão de genes alterados pelo vírus ${ }^{13}$. Com a proliferação hepatocelular descontrolada, há tendência à transformação maligna provavelmente por falha nos mecanismos de reparo ("check-points" do ciclo celular contolados por CDKs, oncogenes e genes supressores tumorais s,23,24 $^{2}$

Embora seja aceito que o VHB possa ser diretamente e indiretamente carcinogênico (indiretamente pela doença hepática necroinflamatória), ainda há muito a ser esclarecido sobre os mecanismos precisos de patogênese.

\section{Infecção pelo vírus da hepatite C (HCV)}

A infecção crônica pelo VHC é outra causa importante de CHC. Estima-se que 170 milhões de pessoas estão cronicamente infectadas pelo vírus ${ }^{13}$. A infecção é predominantemente adquirida na idade adulta, como resultado do uso ilícito de drogas endovenosas e transfusões sanguíneas ou fluidos corporais contaminados. Oitenta por cento ou mais dos infectados agudamente se tornam portadores crônicos ${ }^{19,20,23}$ da doença, e aproximadamente $20 \%$ evolui com cirrose. A relação do $\mathrm{VHC}$ com o $\mathrm{CHC}$ é provavelmente o resultado da necroinflamação hepática induzida pelo vírus (pois não há integração viral aos genomas do hospedeiro), e há evidências recentes que sugerem que o vírus possa agir também como fator carcinogênico direto. Acredita-se que a proteína do core do VHC atue reprimindo a atividade do p53, favorecendo o crescimento tumoral.

Nos casos típicos de hepatite $\mathrm{C}$ crônica, existe estado quiescente por 10 anos ou mais, e a seguir progressão rápida para cirrose. Em idosos, essa progressão é mais lenta, particularmente em casos de hepatites agudas iniciais mais leves. O tempo médio para o aparecimento do CHC após a infecção viral é de 30 anos na maioria dos casos ${ }^{24}$.

A hepatite $\mathrm{C}$ apresenta melhor prognóstico que a hepatite $\mathrm{B}$, mas é potencialmente grave e requer acompanhamento médico rigoroso e prolongado.

\section{Cirrose}

A cirrose hepática é caracterizada por fibrose difusa, progressiva e irreversível, cicatricial (colágeno I e II, e perda das fenestrações sinusoidais), com presença de nódulos regenerativos delimitados por septos fibrosos. Está estritamente relacionada ao aparecimento do $\mathrm{CHC}$, e os fatores etiológicos principais para seu desenvolvimento são a infecção por hepatite B e C e o abuso de álcool, embora outros fatores em menor proporção possam ser desencadeantes (obesidade, hiperlipidemia, diabetes, hemocromatose, doença de Wilson, colangites). Principalmente em países industrializados, há a concomitância da infecção por hepatite associada ao abuso de álcool, mas o mecanismo exato da interação desses mecanismos ainda é incerto ${ }^{3}$.

Idade avançada, duração da cirrose e sexo masculino são fatores de risco importantes para a transformação maligna em pacientes cirróticos ${ }^{8,13,25}$.

Na vigência da cirrose hepática, o "turnover" dos hepatócitos está muito elevado, e atua como potente promotor da transformação tumoral; há também a presença de espécies reativas de oxigênio e nitrogênio geradas pelo processo necroinflamatório crônico, que são mutagênicos e carcinogênicos ${ }^{3,4}$.

Os casos de $\mathrm{CHC}$ relacionadas à cirrose vem aumentando nos últimos anos, principalmente em países desenvolvidos, ao passo que a mortalidade por casos de $\mathrm{CHC}$ não relacionados à ela estão diminuindo ou permanecem estáveis, sendo tal fato atribuído a diagnóstico precoce e aos bons resultados obtidos com o tratamento cirúrgico de tais lesões que hoje atingem em centros especializados taxas de mortalidade relacionadas ao tratamento menores do que $3 \%$.

\section{Exposição a aflatoxinas}

As aflatoxinas são substâncias tóxicas resultantes da atividade metabólica de fungos que se desenvolvem em alimentos e produtos agrícolas. Em condições favoráveis como temperatura, umidade e $\mathrm{pH}$, essas toxinas podem intoxicar seres humanos e animais. A intoxicação (aflatoxicose) pode ocorrer com a ingestão de produtos e subprodutos contaminados (principalmente amendoim, milho, castanhas, feijão, sementes oleaginosas) ${ }^{8,13}$.

Elas são produzidas pelos fungos Aspergillus flavus e Aspergillus paracisticus. Essas aflatoxinas, em especial a aflatoxina B1 (AFB1), são extremamente tóxicas, canceríge- 
nas e tem potencial imunossupressor. O fígado é o primeiro sítio de biotransformação dessas aflatoxinas, que ao serem digeridas ainda são inócuas, porém, são convertidas pelo citocromo P450 em intermediários eletrofílicos que são mutagênicos. No fígado, podem causar lesão parenquimatosa acompanhada de hemorragias ${ }^{13}$. Os efeitos dessa intoxicação podem demorar anos para manifestarem-se.

\section{Medicações}

Anabolizantes esteróides são conhecidos como importantes causadores de toxicidade hepática, que podem levar a alterações estruturais dos hepatócitos por ação oxidante ao elevar o nível de desidrogenase láctica plasmática (liberada pelas células lesadas) e pela diminuição de glutationa (antioxidante). $\mathrm{O}$ uso abusivo de esteróides pode levar a esteatose hepática e ao desenvolvimento de $\mathrm{CHC}^{3}$.

Os contraceptivos orais já foram relatados por ter possível associação com o $\mathrm{CHC}$, porém o mecanismo pelo qual isso acontece ainda é incompreendido, estando estes sim relacionados aos adenomas hepáticos, tumores benignos, com probabilidade de cerca de $8 \%$ de transformação maligna em mulheres usuárias da medicação.

Outros medicamentos que possam causar hepatopatias levando à cirrose também podem ter papel importante no desenvolvimento do $\mathrm{CHC}$, portanto deve-se sempre pesquisar o uso de medicamentos em pacientes portadores de $\mathrm{CHC}$ de etiologia não definida.

\section{Sobrecarga de Ferro}

A sobrecarga hepática de ferro pode acontecer na hemocromatose hereditária e também por sobrecarga de ferro na dieta (mais comum em regiões específicas da África). O consumo de bebidas alcoólicas armazenadas em barris de ferro parece ser o principal responsável por essa sobrecarga. Durante o processo de fermentação, o pH do fermento declina a níveis muito baixos, fazendo com que o ferro dos barris passe para o conteúdo líquido em seu interior. Essa sobrecarga de ferro causa cirrose com frequência, mas o acúmulo de ferro no fígado sem cirrose pode também funcionar como precursor maligno ${ }^{13}$.

\section{Microcistinas}

São substâncias químicas produzidas por cianobactérias/ algas azuis. Essas substâncias são muito tóxicas, e as relacionadas ao CHC são chamadas de hepatotoxinas.

$\mathrm{O}$ CHC causado por elas ocorre apenas em determinadas áreas geográficas da Austrália, Japão, Dinamarca, alguns países da América do Sul, mas principalmente em regiões rurais da China. Nesses locais há alta incidência de CHC, que parece estar relacionado ao consumo de água de rios e lagos que contaminados por microcistinas ${ }^{10}$.

As hepatotoxinas se ligam a receptores de ácidos biliares nos hepatócitos e promovem desorganização dos filamentos intermediários e de actina, polímeros protéicos que compõem o citoesqueleto. Essa desorganização leva à retração dos hepatócitos, provocando a perda do contato entre eles e os capilares sinusóides, fazendo com que o fígado perca sua arquitetura e desenvolva lesões.

\section{Esquistossomose}

Já foi descrita a associação da infecção pelo Schistosoma mansoni em pacientes portadores de carcinoma hepatocelular. Ele e/ou seus ovos causam hepatopatia importante. Os vermes podem ocluir ramos dicotômicos de maior calibre do sistema porta, e quando mortos produzem extensas lesões necroinflamatórias que posteriormente passam por processo cicatricial. Os ovos podem formar granulomas intravasculares que podem interromper a corrente sanguinea portal. Há diminuição da taxa de oxigênio disponível com consequente decréscimo do $\mathrm{pH}$, além da saída de proteínas catiônicas, hidrolases ácidas e neutras que acarretam agressões tissulares. Todas essas alterações podem predispor à transformação maligna.

\section{Prevenção primária}

É a forma mais efetiva de prevenção do $\mathrm{CHC}$, pois consiste em afastar os potenciais agentes carcinogênicos, sejam eles virais, químicos ou físicos. Esse tipo de prevenção basicamente consiste em prevenir a infecção pelo VHB e VHC; prevenir a infecção por Schistossoma mansoni; evitar a sobrecarga de ferro na dieta; incentivo ao não uso de anabolizantes e quantidades exageradas de bebidas alcoólicas; e a prevenção da exposição à aflatoxinas e microcistinas.

Para a Hepatite $\mathrm{B}$, a prevenção primária baseia-se em vacinação contra o vírus (principal fator); um "screening" eficaz em doadores de sangue e hemoderivados; cuidados com o uso de seringas contaminadas e o incentivo de práticas sexuais seguras ${ }^{15,20}$.

As vacinas contra a hepatite $\mathrm{B}$ disponíveis no Brasil são produzidas por engenharia genética por meio da inserção de um plasmídeo contendo o antígeno de superfície do vírus $\mathrm{B}$ (AgHBs) em levedura ${ }^{15,18}$. Essas vacinas não contêm o DNAviral, portanto não causam infecção, mas induzem à produção do anti-HBs.

Ao evitar a infecção, a vacinação contra hepatite B reduz, portanto, a incidência de hepatite crônica, cirrose e CHC na população vacinada ${ }^{4,5,16,20}$, mostrando boa relação custo-efetividade. É altamente efetiva e praticamente isenta de complicações. Elas, quando presentes, são apenas dor no local da aplicação e febre baixa, mais frequentes em adultos do que em crianças nas primeiras doses, tendendo a desaparecer em até $48 \mathrm{~h}$.

Elemento chave para controle eficaz da infecção pelo VHB é o programa de vacinação universal para todos os recém-nascidos, principalmente filhos de gestantes HBsAg positivo. Títulos de anti-HBs superiores a $10 \mathrm{mUI} / \mathrm{mL}$ são considerados protetores ${ }^{15}$.

Após as três doses, cerca de $90 \%$ dos vacinados desenvolvem respostas adequadas de anticorpos; porém em indivíduos vacinados em idades mais avançadas, com a queda da imunogenicidade, a proteção ocorre em somente cerca de $75 \%$. Existem fatores referentes ao hospedeiro (tabagismo, 
obesidade, cirrose, insuficiência renal) que reduzem a resposta à vacina. ${ }^{15}$.Fatores relacionados ao modo de conservação da vacina e local do corpo aplicado também podem interferir na resposta. Eesquema vacinal eficaz confere pelo menos 20 anos de proteção (talvez por toda a vida). A vacina apresenta excelente imunogenicidade, portanto, a sorologia não é indicada após o esquema vacinal; esta só é indicada para indivíduos em grupo de risco: profissionais de saúde, recém-nascidos de mães portadoras da doença e pacientes em diálise. Nesses casos a sorologia deve ser realizada após três meses do esquema vacinal completo $^{15}$. Com o passar do tempo a titulação de anticorpos cai muito, podendo até tornar-se indetectável, porém a proteção contra a infecção e doença sintomática permanece, pois a vacina induz à memória imunológica, motivo pelo qual também não se recomenda a revacinação de imunocompetentes.

A vacinação está indicada para todas as crianças e adolescentes, e para adultos que se enquadrem nos seguintes quesitos: profissionais de saúde, politransfundidos, parceiro sexual de portador crônico, comportamento sexual promíscuo, imigrantes de áreas endêmicas, pacientes submetidos à diálise ${ }^{15,17}$.

Para recém-nascidos de mães portadoras do vírus, é possível que o uso adicional e simultâneo de imunoglobulina humana anti-hepatite B confira fator maior de proteção. Se a criança nascer com $2000 \mathrm{~g}$ ou menos, ou 34 semanas de gestação ou menos, também se recomenda a associação da imunoglobulina juntamente com a vacina ${ }^{15}$.

A imunoglobulina é indicada para adultos nas seguintes situações: parceiros sexuais de portador agudo do vírus da hepatite B e pacientes com exposição a sangue, plasma ou soro $\mathrm{HBsAg}+$ ou de alto risco e imunocomprometidos. A dose padrão de imunoglobulina em adultos é de $0.06 \mathrm{~mL} / \mathrm{kg}^{16}$.

A profilaxia vacinal pós-exposição ao vírus só é indicada se a titulação de anticorpos for inferior a 10UI/L (confirmada por sorologia). Se não for possível obter a titulação no prazo de 24h, é necessária a profilaxia simultânea (vacina + imunoglobulina).

A aplicação da vacina não apresenta riscos teratogênicos para o feto, e não há contra-indicações para vacinação ou aplicação da imunoglobulina em gestantes ou mães que amamentam. O aleitamento materno também não está contraindicado para recém-nascidos de mães AgHBs positivas desde que sejam adequadamente imunizados.

Ainda não há vacina disponível contra o vírus da hepatite $\mathrm{C}$, portanto, a prevenção primária consiste em redução do comportamento de risco, práticas seguras de uso de seringas e extenso controle de sangue, plasma e hemoderivados a serem transfundidos ${ }^{11,19}$.

A exposição acidental a sangue causada por picadas de agulhas, cortes mordidas, ou respingos também apresenta risco de infecção. Esse risco varia de 5 a $40 \%$ para adquirir hepatite B e 3 a $10 \%$ para hepatite $\mathrm{C}$.

$\mathrm{O}$ uso de equipamentos de proteção individual (EPI) para profissionais de saúde é essencial, além de treinamento adequado em medidas de segurança, que reduzem significativamente as lesões e risco de infecção.

A prevenção contra exposição à aflatoxinas é limitada. Consiste em aplicação de fungicidas nas plantações, no entanto, esses métodos podem não ser acessíveis em países que necessitam da prevenção à exposição da AFB1 na dieta, já que o problema ocorre predominantemente em países subdesenvolvidos com baixa renda ${ }^{13}$.

\section{Prevenção Secundária}

Envolve o uso de químicos sintéticos ou naturais que bloqueiem, retardem ou revertam o processo carcinogênico. Essa forma de prevenção deve ser segura, de simples adesão e uso, e acessíveis economicamente.

Existem substâncias que parecem ter papel na desintoxicação do organismo por aflatoxinas. A clorofilina, derivada natural da clorofila, forma complexos estáveis com alguns carcinógenos, incluindo as aflatoxinas, e dessa forma reduz sua biodisponibilidade, e consequentemente seu potencial carcinogênico. A clorofilina também atua como antioxidante, inibindo a peroxidação lipídica. ${ }^{13}$.

O Oltipraz, uma droga usada no tratamento da esquistossomose pode ter algum papel na prevenção do CHC. Ela induz a expressão de enzimas detoxificantes como a Glutationa S-Transferase (importante contra o estresse oxidativo) e também regula a transcrição de genes codificando enzimas antioxidantes, podendo, portanto, ser efetiva na prevenção secundária do $\mathrm{CHC}$ induzido por aflatoxinas.

O dano hepático induzido pelo uso de abusivo de álcool envolve alteração da homeostase, depleção de retinóides e ativação proliferativa dos hepatócitos, mudanças que podem promover a carcinogênese hepática. O mau funcionamento dos receptores retinóides nucleares podem contribuir da mesma forma. A restauração dos níveis de retinóides por suplementação alimentar ou pelo uso de substâncias que inibam o metabolismo dos retinóides (ex: liarozole) podem exercer efeito preventivo secundário ${ }^{14}$.

O papel do retinóides na prevenção do $\mathrm{CHC}$ envolve os seguintes mecanismos: indução da citodiferenciação, inibição da proliferação celular, estimulação da resposta imune, inibição da expressão oncogênica e angiogênese, indução da apoptose, supressão dos fenótipos transformados, modulação da migração, adesão e invasão celulares, redução da colagenase e dos ativadores, do plasminogênio, atividade antioxidante e inativação dos radicais livres, e estimulação do fator de crescimento epidermóide, fator de necrose tumoral e fator de crescimento transformador beta ${ }^{7}$.

A prevenção secundária também inclui a detecção precoce de pacientes portadores de hemocromatose, porfiria e doença de Wilson, para que possam receber tratamento adequado e dessa forma diminuindo o risco de desenvolvimento do carcinoma hepatocelular.

\section{Prevenção terciária}

A necroinflamação hepática que ocorre com maior frequência na forma de cirrose, com menor frequência nas hepatites crônicas e raramente como resultado de hipertensão portal, são condições pré-malignas. Essas condições são agravadas pelo uso de álcool.

Primeiramente deve-se impedir a progressão da hepatite crônica e da cirrose para carcinoma hepatocelular, tratando a necroinflamação induzida pelo vírus. As substâncias usadas 
para esse fim são o interferon alfa (IFN $\alpha) 2$ e a glicirrizina. Os mecanismos pelos quais o IFN $\alpha$ reduz o risco de CHC é incerto. A redução da inflamação hepática e o consequente retardo do processo de fibrose e sua ação contra o vírus são óbvias, mas um mecanismo relacionado ao funcionamento dos genes supressores tumorais parece estar envolvido com a ação anticarcinogênica. A combinação de IFN peguilado e ribavirina sustenta com melhor efetividade a ação antiviral do IFN em pacientes com hepatite $\mathrm{C}$ crônica.

A glicirrizina estimula a produção de IFN $\gamma$, tem papel ativador da imunomodulação, estimula células natural killer (NK) e suprime a inflamação hepática, além de possuir propriedades antioxidantes. Injeções diárias de glicirrizina reduzem os níveis séricos de aminotransferases. A glicirrizina também reduz o risco de recorrência do $\mathrm{CHC}$ após ressecção cirúrgica?

$\mathrm{O}$ tratamento medicamentoso da hepatite B (interferon- alfa-1b, lamivudina, adefovir dipivoxil) atenua as lesões causadas pela hepatopatia crônica, e dessa forma atua indiretamente na prevenção da transformação maligna? .

Ainda são necessários estudos prospectivos mais amplos, para melhor esclarecimento do papel dessas substâncias na prevenção do CHC.

\section{CONCLUSÃO}

Apesar dos avanços científicos e da implementação de medidas para detecção precoce do $\mathrm{CHC}$ em pacientes pertencentes a grupos de risco, não houve melhora na taxa de sobrevida durante as três últimas décadas. O motivo que pode explicar esse fato é que a maioria dos pacientes começa a apresentar sintomas somente quando a doença já está em estágio avançado, e nesse caso as opções terapêuticas são limitadas ${ }^{1,2,22}$.

Papiordanou F, Ribeiro-Jr MAF, Saad WA. Prevention of hepatocellular carcinoma. ABCD Arq Bras Cir Dig 2009;22(2):115-9

ABSTRACT - Background - Hepatocellular carcinoma is one of the major malignant diseases in the world today. Due to the high incidence and difficult prognosis, preventive measures became an important need taking into consideration that its etiology is strictly connected with environmental factors. The main risk factors are the association of hepatocellular carcinoma with chronic hepatitis B and C virus infections and cirrhosis, whatever its cause. Hepatocellular carcinoma is the fifth most common global cancer, representing $85 \%$ of the hepatic primary tumors and it is responsible for nearly two thirds of deaths caused by cancer. Method - Review of the national and international literature in the last 12 years (1997-2009), of 25 articles researched through the electronic databases MedLine, Scielo and Lilacs. Conclusion - Despite of the medical advances and the implementation of precocious measures to detect the hepatocellular carcinoma in patients considered as within risk groups, there was no improvement on the afterlife over the last three decades. The cause that can explain this reality is the absence of symptoms during the early stages of the disease, and by the time the patient looks for medical help, the tumor has frequently reached an advanced stage and the therapeutical options are already too few.

HEADINGS - Hepatocellular, carcinoma. Prevention. Control; risk factors.

\section{REFERÊNCIAS}

1. Blum HE. Hepatocellular carcinoma: therapy and prevention. 2005 Dec 21;11(47):7391-400.

2. Blum HE. Molecular targets for prevention of hepatocellular carcinoma. Dig Dis. 2002;20(1):81-90

3. Chaib E, Ribeiro Junior MAF, Saad WA. Carcinoma Hepatocelular- Dos fatores de risco ao tratamento. São Paulo: Atheneu; 2004

4. Chang MH, Chen TH, Hsu HM, Wu TC, Kong MS, Liang DC, Ni YH, Chen CJ, Chen DS; Taiwan Childhood HCC Study Group. Prevention of hepatocellular carcinoma by universal vaccination against hepatitis B virus: the effect and problems. Clin Cancer Res. 2005 Nov 1;11(21):7953-7

5. Chang MH. Cancer prevention by vaccination against hepatitis B. Recent Results Cancer Res. 2009;181:85-94.

6. Chen DS. Hepatitis $\mathrm{C}$ virus in chronic liver disease and hepatocellular carcinoma in Taiwan. Princess Takamatsu Symp. 1995;25:27-32.

7. Conte, VP. CARCINOMA HEPATOCELULAR. Parte 2. Tratamento. Arq Gastroenterol V. 37 - no. 2 - abr./jun. 2000

8. Cougot D, Neuveut C, Buendia MA. HBV induced carcinogenesis. J Clin Virol. 2005 Dec;34 Suppl 1:S75-8

9. Di Bisceglie AM. Hepatitis B and hepatocellular carcinoma. Hepatology. 2009 May;49(5 Suppl):S56-60

10. Falconer, IR. Tumor Promotion and Liver Injury Caused by Oral Consumption of Cyanobacteria. Environmental Toxicology and Water Quality, 6: 177-184.

11. Franceschi S, Raza SA. Epidemiology and prevention of hepatocellular carcinoma. Cancer Lett. 2008 Dec 11

12. Gonzalez MA, Goldenberg A, Triviño T, Salum MR, Lanzoni VP, Lobo EJ, Rinaldis A, Schraibman V. Resultados do tratamento cirúrgico do carcinoma hepatocelular. Einstein. 2004; 2(4):292-7

13. Kew MC. Prevention of hepatocellular carcinoma HPB (Oxford). 2005;7(1):16-25

14. Kojima S, Okuno M, Matsushima-Nishiwaki R, Friedman SL, Moriwaki H. Acyclic retinoid in the chemoprevention of hepatocellular carcinoma (review). Int J Oncol. 2004 Apr;24(4):797-805
15. Ministério da Saúde. Manual dos Centros de Referência de Imunobiológicos Especiais. Brasília: Fundação Nacional de Saúde; 2001. p. 59-63

16. O'Brien TR, Kirk G, Zhang M. Hepatocellular carcinoma: paradigm of preventive oncology. Cancer J. 2004 Mar-Apr;10(2):67-73

17. Oberle MW, Shapiro CN, Lanier AP. Preventing hepatitis B in people in close contact with hepatocellular carcinoma patients. Public Health Rep. 1997 JanFeb;112(1):63-5

18. Organização Mundial de Gastroenterologia, Set 2008 Guia Prática da OMGE: Hepatite B.

19. Ozaras R, Tahan V. Acute hepatitis C: prevention and treatment. Expert Rev Anti Infect Ther. 2009 Apr;7(3):351-61

20. Pár A. Prophylaxis and treatment of chronic viral hepatitis as the prevention of hepatocellular carcinoma. Orv Hetil. 2009 Jan 4;150(1):19-26

21. Schott E, Bergk A, Berg T. Strategies for the prevention of hepatocellular carcinoma in the context of chronic viral hepatitis. Z Gastroenterol. 2008 Jan;46(1):69-80

22. Spangenberg HC, Thimme R, Blum HE. Advances in prevention and diagnosis of hepatocellular carcinoma. Expert Rev Gastroenterol Hepatol. 2008 Jun;2(3):425-33

23. Tan A, Yeh SH, Liu CJ, Cheung C, Chen PJ. Viral hepatocarcinogenesis: from infection to cancer. Liver Int. $2008 \mathrm{Feb}$;28(2):175-88

24. Ueno Y, Sollano JD, Farrell GC. Prevention of hepatocellular carcinoma complicating chronic hepatitis C. J Gastroenterol Hepatol. 2009 Apr;24(4):531-6

25. Zanetti AR, Van Damme P, Shouval D. The global impact of vaccination against hepatitis B: a historical overview. Vaccine. 2008 Nov 18;26(49):6266-73. Epub 2008 Oct 9
Fonte de financiamento: não há Conflito de interesse: não há Recebido para publicação: 21/02/2009 Aceito para publicação: 14/04/2009 